\title{
Fourteen Points of Agreement with Official Government Reports on the World Trade Center Destruction
}

\author{
Steven E. Jones* ${ }^{*}$, , Frank M. Legge ${ }^{2}$, Kevin R. Ryan ${ }^{3}$, Anthony F. Szamboti*,4 and James R. \\ Gourley $^{5}$ \\ ${ }^{I}$ S\&J Scientific Co., Provo, UT, 84604, USA \\ ${ }^{2}$ Logical Systems Consulting, Perth, Western Australia, Australia \\ ${ }^{3}$ Bloomington, IN 47401, USA \\ ${ }^{4}$ Blackwood, NJ 08012, USA \\ ${ }^{5}$ Dallas, TX 75231, USA
}

\begin{abstract}
Reports by FEMA and NIST lay out the official account of the destruction of the World Trade Center on $9 / 11 / 2001$. In this Letter, we wish to set a foundation for productive discussion and understanding by focusing on those areas where we find common ground with FEMA and NIST, while at the same time countering several popular myths about the WTC collapses.
\end{abstract}

Keywords: World Trade Center, 9/11, Total collapse, Pancake theory, Momentum conservation, Residues.

\section{INTRODUCTION}

On September 11, 2001, the Twin Towers of the World Trade Center (WTC) were hit by airplanes. Total destruction of these high-rises at near free-fall speeds ensued within two hours, and another high-rise which was not hit by a plane (WTC 7) collapsed about seven hours later at 5:20 p.m.

The US Congress laid out the charge specifically to the National Institute of Standards and Technology (NIST) to "Determine why and how WTC 1 and WTC 2 collapsed following the initial impacts of the aircraft and why and how WTC 7 collapsed" [1]. The Federal Emergency Management Agency (FEMA) was acting with a similar motivation in their earlier study of these tragic collapses [2]. NIST and FEMA were not charged with finding out how fire was the specific agent of collapse, yet both evidently took that limited approach while leaving open a number of unanswered questions. Our goal here is to set a foundation for scientific discussion by enumerating those areas where we find agreement with NIST and FEMA. Understanding the mechanisms that led to the destruction of the World Trade Center will enable scientists and engineers to provide a safer environment for people using similar buildings and benefit firefighters who risk their lives trying to save others.

\section{DISCUSSION}

\section{WTC 7 Collapse Issue}

FEMA: "The specifics of the fires in WTC 7 and how they caused the building to collapse remain unknown at this

*Address correspondence to this author at the S\&J Scientific Company, 190 East 4680 North, Provo, Utah, USA; Tel: 801-735-5885; Fax: 801-4220553; E-mail: HardEvidence@ gmail.com

4 Hawthorne Court, Blackwood, NJ, 08012, USA; Tel: 856-228-4747; E-mail: tonyszamboti@comcast.net time. Although the total diesel fuel on the premises contained massive potential energy, the best hypothesis has only a low probability of occurrence. Further research, investigation, and analyses are needed to resolve this issue" [2].

FEMA analyzed the remarkable collapse of WTC building 7, the 47-story skyscraper that, even though it was not hit by a plane, collapsed about seven hours after the second Tower collapse. We certainly agree that FEMA's best firebased hypothesis "has only a low probability of occurrence." NIST's final report on WTC 7 has been long delayed and is eagerly awaited [3]. Apparently it is difficult to fully explain the complete and rapid collapse of WTC 7 with a fire-based hypothesis alone.

\section{Withstanding Jet Impact}

FEMA: "The WTC towers had been designed to withstand the accidental impact of a Boeing 707 seeking to land at a nearby airport..." [2]

NIST: "Both WTC 1 and WTC 2 were stable after the aircraft impact, standing for $102 \mathrm{~min}$ and $56 \mathrm{~min}$, respectively. The global analyses with structural impact damage showed that both towers had considerable reserve capacity" [4].

Yes, we agree, as do previously published reports: "The 110-story towers of the World Trade Center were designed to withstand as a whole the forces caused by a horizontal impact of a large commercial aircraft. So why did a total collapse occur?" [5]

John Skilling, a leading structural engineer for the WTC Towers, was interviewed in 1993 just after a bomb in a truck went off in the North Tower: 
"We looked at every possible thing we could think of that could happen to the buildings, even to the extent of an airplane hitting the side," said John Skilling, head structural engineer....

Concerned because of a case where an airplane hit the Empire State Building [which did not collapse], Skilling's people did an analysis that showed the towers would withstand the impact of a Boeing 707.

"Our analysis indicated the biggest problem would be the fact that all the fuel (from the airplane) would dump into the building. There would be a horrendous fire. A lot of people would be killed," he said. "The building structure would still be there."

Skilling - a recognized expert in tall buildings doesn't think a single 200-pound car bomb would topple or do major structural damage to a Trade Center tower. The supporting columns are closely spaced and even if several were disabled, the others would carry the load.

...Although Skilling is not an explosives expert, he says there are people who do know enough about building demolition to bring a structure like the Trade Center down.

"I would imagine that if you took the top expert in that type of work and gave him the assignment of bringing these buildings down with explosives, I would bet that he could do it." [6]

Thus, Skilling's team showed that a commercial jet would not bring down a WTC Tower, just as the Empire State Building did not collapse when hit by an airplane, and he explained that a demolition expert using explosives could demolish the buildings. We find we are in agreement.

\section{Pancake Theory Not Supported}

NIST: "NIST's findings do not support the "pancake theory" of collapse, which is premised on a progressive failure of the floor systems in the WTC towers... Thus, the floors did not fail progressively to cause a pancaking phenomenon" [3].

Agreed: the "pancake theory of collapse" is incorrect and should be rejected. This theory of collapse was proposed by the earlier FEMA report and promoted in the documentary "Why the Towers Fell" produced by NOVA [7]. The "pancake theory of collapse" is strongly promoted in a Popular Mechanics article along with a number of other discredited ideas $[8,9]$. We, on the other hand, agree with NIST that the "pancake theory" is not scientifically tenable and ought to be set aside in serious discussions regarding the destruction of the WTC Towers and WTC 7.

\section{Massive Core Columns}

NIST: "As stated above, the core columns were designed to support approximately $50 \%$ of the gravity loads" [4]. "The hat-truss tied the core to the perimeter walls of the towers, and thus allowed the building to withstand the effects of the aircraft impact and subsequent fires for a much longer time-enabling large numbers of building occupants to evacuate safely" [10].

"Pacific Car and Foundry of Seattle, Washington, fabricated the closely spaced exterior wall column panels that gave the buildings their instantly recognizable shape. Stanray Pacific of Los Angeles, Cal, fabricated the enormous box and wide-flange columns that made up the core... The core of the building, which carried primarily gravity loads, was made up of a mixture of massive box columns made from three-story long plates, and heavy rolled wide-flange shapes." "The core columns were designed to carry the building gravity loads and were loaded to approximately $50 \%$ of their capacity before the aircraft impact.... the exterior columns were loaded to only approximately $20 \%$ of their capacity before the aircraft impact" [11].

We totally agree that the WTC Towers included "massive" interconnected steel columns in the cores of the buildings, in addition to the columns in the outside walls. The central core columns bore much of the gravity loads so the Towers were clearly NOT hollow. Yet the false notion that the Towers were "hollow tubes" with the floors supported just by the perimeter columns seems to have gained wide acceptance. For example, an emeritus structural engineering professor asserted, "The structural design of the towers was unique in that the supporting steel structure consisted of closely spaced columns in the walls of all four sides. The resulting structure was similar to a tube..." [12].

The fact is the Towers were constructed with a substantial load-supporting core structure as well as perimeter columns - and on this point we agree with NIST in dispelling false popular notions.

\section{Essentially in Free Fall}

NIST: [Question:] "How could the WTC towers collapse in only 11 seconds (WTC 1) and 9 seconds (WTC 2)speeds that approximate that of a ball dropped from similar height in a vacuum (with no air resistance)?" [Answer:] ...As documented in Section 6.14.4 of NIST NCSTAR 1, these collapse times show that: "... the structure below the level of collapse initiation offered minimal resistance to the falling building mass at and above the impact zone. The potential energy released by the downward movement of the large building mass far exceeded the capacity of the intact structure below to absorb that energy through energy of deformation. Since the stories below the level of collapse initiation provided little resistance to the tremendous energy released by the falling building mass, the building section above came down essentially in free fall, as seen in videos" [3].

We agree with some of this, that the building "came down essentially in free fall, as seen in videos." This is an important starting point. (Because of obscuring dust clouds, it is difficult to determine the exact fall times, but the statement that the buildings "came down essentially in free fall" seems correct when accelerations are viewed, for the WTC Towers and also for WTC 7.) [13, 14] Further, we agree with NIST that "the stories below the level of collapse initiation provided little resistance" to the fall - but we ask - how could that be? NIST mentions "energy of deformation" which for the huge core columns in the Towers would be considerable, and they need to be quantitative about it 
(which they were not) in order to claim that the "intact structure" below would not significantly slow the motion.

Beyond that, NIST evidently neglects a fundamental law of physics in glibly treating the remarkable "free fall" collapse of each Tower, namely, the Law of Conservation of Momentum. This law of physics means that the hundreds of thousands of tons of material in the way must slow the upper part of the building because of its mass, independent of deformation which can only slow the fall even more. (Energy and Momentum must both be conserved.)

Published papers have argued that this negligence by NIST (leaving the near-free-fall speeds unexplained) is a major flaw in their analysis [13, 14]. NIST ignores the possibility of controlled demolitions, which achieve complete building collapses in near free-fall times by moving the material out of the way using explosives. So, there is an alternative explanation that fits the data without violating basic laws of physics. We should be able to agree from observing the near-free-fall destruction that this is characteristic of controlled demolitions and, therefore, that controlled demolition is one way to achieve complete collapse at near free-fall speed. Then we are keen to look at NIST's calculations of how they explain near-free-fall collapse rates without explosives.

We await an explanation from NIST which satisfies Conservation of Momentum and Energy for the rapid and complete destruction of all three WTC skyscrapers on 9/11, or a discussion of alternative hypotheses that are consistent with momentum and energy conservation in these near-free-fall events.

\section{Fire Endurance Tests, No Failure}

NIST: "NIST contracted with Underwriters Laboratories, Inc. to conduct tests to obtain information on the fire endurance of trusses like those in the WTC towers.... All four test specimens sustained the maximum design load for approximately 2 hours without collapsing... The Investigation Team was cautious about using these results directly in the formulation of collapse hypotheses. In addition to the scaling issues raised by the test results, the fires in the towers on September 11, and the resulting exposure of the floor systems, were substantially different from the conditions in the test furnaces. Nonetheless, the [empirical test] results established that this type of assembly was capable of sustaining a large gravity load, without collapsing, for a substantial period of time relative to the duration of the fires in any given location on September 11" [4].

We agree that NIST had actual fire tests completed and that all four "trusses like those in the WTC towers" survived the fire-endurance testing "without collapsing." We also agree that "the fires in the towers on September $11 \ldots$ were substantially different from the conditions in the test furnaces;" the test furnaces were hotter and burned longer. NIST may wish to perform a series of different tests in an endeavor to discover some other hypothesis for collapse initiation. As it stands, however, we have no physical evidence supporting the concept of total collapse due to fire from real fire-endurance tests. On the contrary, these real-life tests indicate that the buildings should not have completely collapsed. In addition, we have hundreds of cases of fires in tall steel-frame buildings and complete collapse has never occurred.

But experts said no building like it [WTC7], a modern, steel-reinforced high-rise, had ever collapsed because of an uncontrolled fire, and engineers have been trying to figure out exactly what happened and whether they should be worried about other buildings like it around the country.... Although the fireproofing was intended to withstand ordinary fires for at least two hours, experts said buildings the size of 7 World Trade Center that are treated with such coatings have never collapsed in a fire of any duration. Most of three other buildings in the complex, 4, 5 and 6 World Trade, stood despite suffering damage of all kinds, including fire [15].

Fire engineering expert Norman Glover agrees:

Almost all large buildings will be the location for a major fire in their useful life. No major high-rise building has ever collapsed from fire... The WTC [itself] was the location for such a fire in 1975; however, the building survived with minor damage and was repaired and returned to service [16].

Yet three such high-rise buildings (WTC 1, 2 and 7) completely collapsed on a single day, 9/11/2001, and could not be returned to service. There is much left to learn here.

\section{Fires of Short Duration}

NIST: "The initial jet fuel fires themselves lasted at most a few minutes" [4]. "At any given location, the duration of [air, not steel] temperatures near $1,000{ }^{\circ} \mathrm{C}$ was about $15 \mathrm{~min}$ to $20 \mathrm{~min}$. The rest of the time, the calculated temperatures were near $500{ }^{\circ} \mathrm{C}$ or below" [4].

We agree. But then, given that the fires were brief and patchy, how did both towers experience sudden-onset failure of structural steel over a broad area in each tower and how could the collapses of all three WTC high-rises have been so symmetrical and complete? [13, 14, 17] We seek discussion on these points.

\section{WTC Fires Did Not Melt Steel}

NIST: "In no instance did NIST report that steel in the WTC towers melted due to the fires. The melting point of steel is about 1,500 degrees Celsius (2,800 degrees Fahrenheit). Normal building fires and hydrocarbon (e.g., jet fuel) fires generate temperatures up to about 1,100 degrees Celsius (2,000 degrees Fahrenheit). NIST reported maximum upper layer air temperatures of about 1,000 degrees Celsius (1,800 degrees Fahrenheit) in the WTC towers (for example, see NCSTAR 1, figure 6-36)" [3].

Agreed. We also find agreement with Prof. Thomas Eagar on this point:

The fire is the most misunderstood part of the WTC collapse. Even today, the media report (and many scientists believe) that the steel melted. It is argued that the jet fuel burns very hot, especially with so much fuel present. This is not true.... The temperature of the fire at the WTC was not un- 
usual, and it was most definitely not capable of melting steel [18].

We are in remarkable agreement, then: the WTC fires were not capable of melting steel. Of course, NIST then may have trouble explaining the molten material flowing out of the South Tower just before its collapse, as well as evidence for temperatures much higher than NIST's reported $1,100{ }^{\circ} \mathrm{C}$ [13]. We offer to discuss explanations for the observed high temperatures.

\section{Destruction of WTC Steel Evidence}

NIST: "NIST possesses 236 structural steel elements from the World Trade Center (WTC) buildings. These pieces represent a small fraction of the enormous amount of steel examined at the various recovery yards where the debris was sent as the WTC site was cleared. It is estimated that roughly 0.25 percent to 0.5 percent of the 200,000 tons of steel used in the construction of the two towers was recovered." "The lack of WTC 7 steel precludes tests on actual material from the structure..." [1].

Thus, only a tiny fraction of steel was analyzed from the WTC Towers, and none of the WTC 7 steel was analyzed by NIST. What happened to the rest of the steel from the crime scene?

For more than three months, structural steel from the World Trade Center has been and continues to be cut up and sold for scrap. Crucial evidence that could answer many questions about high-rise building design practices and performance under fire conditions is on the slow boat to China, perhaps never to be seen again in America until you buy your next car.

Such destruction of evidence shows the astounding ignorance of government officials to the value of a thorough, scientific investigation of the largest fire-induced collapse in world history. I have combed through our national standard for fire investigation, NFPA 921, but nowhere in it does one find an exemption allowing the destruction of evidence for buildings over 10 stories tall [19].

And although only a small fraction of the steel was saved for testing, it is clear that an "enormous amount" of the WTC steel was examined either for or by NIST, and the samples selected were chosen for their identified importance to the NIST investigation [20].

We agree that only a "small fraction of the enormous amount of steel" from the Towers was spared and the rest was rapidly recycled. The destruction of about $99 \%$ of the steel, evidence from a crime scene, was suspicious and probably illegal, hopefully we can agree to that.

\section{Unusual Bright Flame and Glowing Liquid (WTC 2)}

NIST: "An unusual flame is visible within this fire. In the upper photograph \{Fig 9-44\} a very bright flame, as opposed to the typical yellow or orange surrounding flames, which is generating a plume of white smoke, stands out" [4].

"NIST reported (NCSTAR 1-5A) that just before 9:52 a.m., a bright spot appeared at the top of a window on the 80th floor of WTC 2, four windows removed from the east edge on the north face, followed by the flow of a glowing liquid. This flow lasted approximately four seconds before subsiding. Many such liquid flows were observed from near this location in the seven minutes leading up to the collapse of this tower" [3].

We agree and congratulate NIST for including these observations of an "unusual flame... which is generating a plume of white smoke" [4] "followed by the flow of a glowing liquid" having "an orange glow" [3]. With regard to the "very bright flame... which is generating a plume of white smoke", NIST effectively rules out burning aluminum, because "Aluminum is not expected to ignite at normal fire temperatures..." [3].

Again, we agree.

The origins of this very bright flame and of the associated flow of an orange-glowing liquid remain open questions in the NIST report. NIST opened a very appropriate line of investigation by publishing these significant clues from the data, $[3,4]$ providing an important starting point for further discussion which we seek.

\section{High-Temperature Steel Attack, Sulfidation}

FEMA (based on work by a Worchester Polytechnic Institute investigative team): "Sample 1 (From WTC 7)... Evidence of a severe high temperature corrosion attack on the steel, including oxidation and sulfidation with subsequent intergranular melting, was readily visible in the near-surface microstructure... Sample 2 (From WTC 1 or WTC 2)... The thinning of the steel occurred by high temperature corrosion due to a combination of oxidation and sulfidation. ...The severe corrosion and subsequent erosion of Samples 1 and 2 are a very unusual event. No clear explanation for the source of the sulfur has been identified... A detailed study into the mechanisms of this phenomenon is needed..." [2]

We agree that the physical evidence for "severe high temperature corrosion attack" involving sulfur is compelling. Here we have grounds for an interesting discussion: How were "severe high temperatures" reached in the WTC buildings? What is the source of the sulfur that attacked the steel in these buildings? The answers to these questions may help us find the explanation for the "total collapse" of the Towers and WTC 7 that we are all looking for.

The WPI researchers published their results [2,21] and called for "a detailed study" of this "high-temperature" "oxidation and sulfidation" phenomenon. Yet the results were unfortunately ignored by NIST in their subsequent reports on the Towers' destruction $[3,4]$. Their failure to respond to this documented anomaly is a striking phenomenon in itself. Perhaps NIST will explain and correct this oversight by considering the high-temperature sulfidation data in their long overdue report on the collapse of WTC 7. The existence of severe high temperatures in the WTC destruction is by now very well established [22]. It appears that NIST has inadvertently overlooked this evidence and we offer to investigate the matter with them, in pursuit of understanding and security.

\section{Computer Modeling and Visualizations}

NIST: "The more severe case (which became Case B for WTC 1 and Case D for WTC 2) was used for the global 
analysis of each tower. Complete sets of simulations were then performed for Cases B and D. To the extent that the simulations deviated from the photographic evidence or eyewitness reports [e.g., complete collapse occurred], the investigators adjusted the input, but only within the range of physical reality. Thus, for instance...the pulling forces on the perimeter columns by the sagging floors were adjusted... [4] "The primary role of the floors in the collapse of the towers was to provide inward pull forces that induced inward bowing of perimeter columns [4]. "The results were a simulation of the structural deterioration of each tower from the time of aircraft impact to the time at which the building became unstable, i.e., was poised for collapse... [4].

We agree that NIST resorted to complex computer simulations and no doubt "adjusted the input" to account for the Towers' destruction, after the fire-endurance physical tests did not support their preordained collapse theory.

But the end result of such tweaked computer models, which were provided without visualizations and without sufficient detail for others to validate them, is hardly compelling. An article in the journal New Civil Engineer states:

World Trade Center disaster investigators [at NIST] are refusing to show computer visualisations of the collapse of the Twin Towers despite calls from leading structural and fire engineers, NCE has learned. Visualisations of collapse mechanisms are routinely used to validate the type of finite element analysis model used by the [NIST] investigators. ...A leading US structural engineer said NIST had obviously devoted enormous resources to the development of the impact and fire models. "By comparison the global structural model is not as sophisticated," he said. "The software used [by NIST] has been pushed to new limits, and there have been a lot of simplifications, extrapolations and judgment calls" [23].

Further detailed comments on the NIST computer simulations are provided by Eric Douglas [24].

We would like to discuss the computer modeling and extrapolations made by NIST and the need for visualizations using numerical and graphical tools to scrutinize and validate the finite-element analysis.

\section{Total Collapse Explanation Lacking}

NIST: "This letter is in response to your April 12, 2007 request for correction... we are unable to provide a full explanation of the total collapse" [25].

This admission by NIST after publishing some 10,000 pages on the collapse of the Towers shows admirable candor, yet may come as a bit of a shock to interested parties including Congress, which commissioned NIST to find a full explanation.

We agree that NIST so far has not provided a full explanation for the total collapse. Indeed they take care to explain that their report stops short of the collapse, only taking the investigation up to the point where each Tower "was poised for collapse" [4]. We offer to help find that elusive "full explanation of the total collapse" of the WTC Towers which killed so many innocent people, in the hope that it does not happen again. We have a few ideas and can back these up with experimental data $[13,22]$. Our interest is in physical evidence and analysis leading to a full understanding of the destruction of the WTC.

\section{Search for Explosive or Thermite Residues}

From a NIST FAQ: [Question: ] "Did the NIST investigation look for evidence of the WTC towers being brought down by controlled demolition? Was the steel tested for explosives or thermite residues? The combination of thermite and sulfur (called thermate) "slices through steel like a hot knife through butter." [Answer: ] NIST did not test for the residue of these compounds in the steel" [3].

We agree; there is no evidence that NIST tested for residues of thermite or explosives. This is another remarkable admission. Probing for residues from pyrotechnic materials including thermite in particular, is specified in fire and explosion investigations by the NFPA 921 code:

Unusual residues might remain from the initial fuel. Those residues could arise from thermite, magnesium, or other pyrotechnic materials [26].

Traces of thermite in residues (solidified slag, dust, etc.) would tell us a great deal about the crime and the cause of thousands of injuries and deaths. This is standard procedure for fire and explosion investigations. Perhaps NIST will explain why they have not looked for these residues? The code specifies that fire-scene investigators must be prepared to justify an exclusion [26].

NIST has been asked about this important issue recently, by investigative reporter Jennifer Abel:

Abel: "..what about that letter where NIST said it didn't look for evidence of explosives?" Neuman [spokesperson at NIST, listed on the WTC report]: "Right, because there was no evidence of that." Abel: But how can you know there's no evidence if you don't look for it first? Neuman: "If you're looking for something that isn't there, you're wasting your time... and the taxpayers' money." [27].

The evident evasiveness of this answer might be humorous if not for the fact that NIST's approach here affects the lives of so many innocent people. We do not think that looking for thermite or other residues specified in the NFPA 921 code is "wasting your time." We may be able to help out here as well, for we have looked for such residues in the WTC remains using state-of-the-art analytical methods, especially in the voluminous toxic dust that was produced as the buildings fell and killed thousands of people, and the evidence for thermite use is mounting. [13, 22]

\section{CONCLUSIONS}

We have enumerated fourteen areas where we are in agreement with FEMA and NIST in their investigations of the tragic and shocking destruction of the World Trade Center. We agree that the Towers fell at near free-fall speed and that is an important starting point. We agree that several popular myths have been shown to be wrong, such as the idea that steel in the buildings melted due to the fires, or that the Towers were hollow tubes, or that floors "pancaked" to account for total Tower collapses. We agree that the collapse of the 47-story WTC 7 (which was not hit by a jet) is hard to 
explain from the point of view of a fire-induced mechanism and that NIST has refused (so far) to look for residues of explosives [3, 22, 27]. Our investigative team would like to build from this foundation and correspond with the NIST investigation team, especially since they have candidly conceded (in a reply to some of us in September 2007):

“...we are unable to provide a full explanation of the total collapse" [25].

We are offering to discuss these matters in a civil manner as a matter of scientific and engineering courtesy and civic duty. The lives of thousands of people may very well depend on it.

\section{ACKNOWLEDGEMENTS}

Many thanks for useful discussions with Jim Hoffman, Dr. Gregory Jenkins, Dr. Jeffrey Farrer, Prof. Kenneth Kuttler, Prof. David R. Griffin, Gregg Roberts, Brad Larsen, Gordon Ross, Prof. David Griscom, Prof. Graeme MacQueen, and researchers at AE911Truth.org and STJ911.org.

\section{REFERENCES}

[1] S. W. Banovic, "Federal building and fire safety investigation of the World Trade Center disaster: Steel inventory and identification, NIST NCSTAR1-3B". Gaithersburg, MD: National Institute of Standards and Technology, September 2005.

[2] Federal Emergency Management Agency (FEMA), World Trade Center building performance study: Preliminary observations, and recommendations, Report FEMA 403. Washington, D.C.: Federal Emergency Management Agency, May 2002.

[3] S. Sunder, W. Grosshandler, H. S. Lew, et al. "National Institute of Standards and Technology (NIST) federal building and fire safety investigation of the World Trade Center disaster, answers to frequently asked questions", Gaithersburg, MD: National Institute of Standards and Technology, August 30, 2006. [Online]. Available: NIST, http://wtc.nist.gov. [Accessed March 17, 2008].

[4] S. Sunder, W. Grosshandler, H. S. Lew, et al. "Final report on the collapse of the World Trade Center towers, NIST NCSTAR . Gaithersburg”, MD: National Institute of Standards and Technology, September 2005.

[5] Z. P. Bazant and Y. Zhou, "Why did the World Trade Center collapse? Simple analysis", J. Eng. Mech., vol. 128, pp. 2-6, January 2002.

[6] E. Nalder, "Twin towers engineered to withstand jet collision", Seattle Times, February 27, 1993. [Online]. Available: http:// archives.seattletimes.nwsource.com/cgi-

bin/texis.cgi/web/vortex/display?slug $=1687698 \&$ date $=19930227$ [Accessed April 5, 2008].

[7] Public Broadcasting System, "Why the Towers fell", Public Broadcasting System, 2002. [Online]. Available: http://www.pbs.org/ wgbh/nova/transcripts/2907_wtc.html [Accessed March 17, 2008].

[8] J. B. Meigs, D. Dunbar, B. Reagan, et al. "Debunking the $9 / 11$ myths, special report", Popular Mechanics, vol. 182, pp. 70-81, March 2005

[9] D. R. Griffin, Debunking 9/11 debunking: "An answer to Popular Mechanics and other defenders of the official conspiracy theory", Northampton, MA: Interlink Books, 2007.
[10] S. Sundar, Opening remarks of Dr. S. Shyam Sunder (NIST), May 2006. [Online]. Available: NIST, http://wtc.nist.gov/media/ Sunder_Progressive\%20Collapse_Remarks_050106.pdf [Accessed March 27, 2008].

[11] S. W. Banovic, T. Foecke, W.E. Luecke, et al. "The role of metallurgy in the NIST investigation of the World Trade Center towers collapse",JOM, vol. 59, no. 11, pp. 22-29, November 2007.

[12] D. A. Firmage. (April 10, 2006). "Refuting 9/11 conspiracy theory", The College Times, p. A6.

[13] S. E. Jones, "Why indeed did the WTC buildings completely collapse?", Journal of 9/11 Studies, vol. 3, pp. 1-47, September 2006 [Online]. Available: www.journalof911studies.com [Accessed March 17, 2008].

[14] F. Legge and T. Szamboti, " $9 / 11$ and the twin towers: Sudden collapse initiation was impossible", Journal of 9/11 Studies, vol 18, pp. 1-3, December 2007. [Online]. Available: www. journalof 911 studies.com [Accessed March 17, 2008].

[15] J. Glanz, "A nation challenged; the site: Engineers have a culprit in the strange collapse of 7 World Trade Center: Diesel fuel", New York Times, November 29, 2001, p. B9.

[16] N. J. Glover, "Collapse lessons", Fire Engineering, October 2002, p. 97.

[17] D. L. Griscom, "Hand-waving the physics of 9/11", Journal of 9/11 Studies, Letters, February 8, 2007. [Online]. Available: www.journalof911studies.com [Accessed March 17, 2008].

[18] T. W. Eagar and C. Musso, "Why did the World Trade Center collapse? Science, engineering, and speculation", JOM, vol. 53, no. 12, pp. 8-11, December 2001.

[19] W. Manning, "Selling out the investigation", Fire Engineering, January 2002, p. 4.

[20] J. Gourley, R. McIlvaine, W. Doyle, S. E. Jones, K. Ryan and R. Gage, "Appeal filed with NIST pursuant to earlier request for correction", Journal of 9/11 Studies, 17 pp. 1-16. [Online]. Available: www.journalof911studies.com [Accessed March 17, 2008].

[21] J. R. Barnett, R. R. Biederman and R. D. Sisson, Jr., "An initial microstructural analysis of A36 steel from WTC building 7", JOM, vol. 53 , no. 12, p. 18, December 2001.

[22] S. E. Jones, J. Farrer, G. S. Jenkins, et al. "Extremely high temperatures during the World Trade Center destruction", Journal of 9/11 Studies, vol. 19, pp.1-11, January 2008. [Online]. Available: www.journalof911studies.com [Accessed March 17, 2008].

[23] D. Parker, "WTC investigators resist call for collapse visualisation", New Civil Engineer, November 1, 2005. [Online]. Available: http://www.nce.co.uk/news/2005/11/wtc_investigators_resist_call_ for_collapse_visualisation.html [Accessed April 8, 2008].

[24] E. Douglas, "The NIST WTC investigation-- how real was the simulation? A review of NIST NCSTAR 1", Journal of 9/11 Studies, vol. 6, pp. 1-28, December 2006. [Online]. Available: www.journalof911studies.com [Accessed March 17, 2008].

[25] C. S. Fletcher (NIST), "Response to request for correction", Journal of 9/11 Studies, vol. 17, pp. 17-23, November 2007. [Online]. Available: www.journalof911studies.com [Accessed March 17, 2008].

[26] National Fire Protection Association, "Guide for fire and explosion investigations", NFPA 921. [Online]. Available: http://www.nfpa. org/aboutthecodes/AboutTheCodes.asp?DocNum=921 [Accessed March 17, 2008].

[27] J. Abel, "Theories of 9/11", Hartford Advocate, Hartford, Connecticut, January 29, 2008. [Online]. Available: http://www. hartfordadvocate.com/article.cfm?aid=5546 with reply: http:// www.hartfordadvocate.com/article.cfm?aid=5674 [Accessed March 17, 2008]. 